\title{
Servikal radikülopatide anterior servikal diskektomi ve füzyon
}

\author{
Anterior cervical discectomy and fusion
}

\author{
Uzay Erdoğan, A. Ender Ofluoğlu \\ Bakırköy Prof. Dr. Mazhar Osman Ruh Sağlığı ve Sinir Hastalıkları Eğitim Araştırma Hastanesi, \\ Beyin ve Sinir Cerrahisi Kliniği, İstanbul, Türkiye
}

\begin{abstract}
Anterior servikal diskektomi ve füzyon (ASDF), semptomatik servikal dejeneratif disk hastalığının tedavisinde halen "altın standart" olan ve yaygın olarak uygulanan cerrahi işlemlerden biridir. Anterior servikal cerrahiyi takiben en iyi sonuç, iyi dekompresyon, hızlı ve sağlam kemik füzyonu ve biyomekanik yapının normale yakın restorasyonuna bağlıdır. ASDF cerrahisi, omurilik ve foramenlerin doğrudan dekompresyonuna izin verir; bu nedenle, bu prosedür doğru hastada ve doğru şekilde uygulandığında, omurga cerrahisinde en iyi sonuçların alındığı cerrahilerdendir. Bu derlemede, servikal radikülopatinin cerrahi tedavisinde sıklıkla uygulanmakta olan diskektomi ve füzyon prosedürü anlatılacaktır.
\end{abstract}

Anahtar sözcükler: anterior servikal diskektomi; servikal disk hastalığı; füzyon
Anterior cervical discectomy and fusion (ACDF) is one of the most common procedures which is almost a "gold standard" in the treatment of symptomatic cervical degenerative disc disease. Good results following the anterior cervical spine surgery depends on good decompression, rapid and robust bone fusion, and nearly normal restoration of the biomechanical structure. ACDF surgery allows for direct decompression of the spinal cord and foramina; so when applied in the right patient and correctly, it is one of the procedures that offer the best results in spinal surgery. In this review, the discectomy and fusion procedure which is frequently applied in the surgical treatment of cervical radiculopathy will be explained.

Key words: anterior cervical discectomy; cervical disc disease; fusion

Servikal hastalıklarda kullanılmakta olan prosedürler içinde; anterior servikal diskektomi ve füzyon (ASDF), anterior servikal korpektomi ve füzyon, füzyonlu veya füzyonsuz posterior servikal dekompresyon veya servikal disk artroplastisi sayılabilir. ${ }^{[3]}$

Servikal radikülopati tedavisinde ASDF etkili bir yöntemdir. Cloward ve Smith-Robinson'un geliştirdikleri ASDF, uzun zamandan beri geleneksel olarak uygulanan ve halen servikal disk hastalığının tedavisinde altın standart olarak tanımlanan cerrahi yöntemdir. ${ }^{[2,4,5]}$ Sadece basit diskektomi ile füzyonsuz disk cerrahisi günümüzde halen servikal disk patolojilerinde yapılmakta ise de, boş kalan mesafede sonradan oluşabilecek segmental kifoz ve bunun sonucunda ortaya çıkacak aksiyel boyun ağrısı nedeni ile artık tavsiye edilmemektedir. Ortaya çıkan segmental kifoz, disk mesafesinde çökme, foramenlerde restenoz ve semptomların tekrar geri dönmesine neden olacağı bilinmektedir. ${ }^{[6-8]}$

- Illetişim adresi: Doç. Dr. A. Ender Ofluoğlu, Zuhuratbaba Mah. Akıl Hastanesi Cad. No: 25, Bakırköy, İstanbul Tel: 0532 - 4410928 e-posta: enderofluoglu@yahoo.com

- Geliș tarihi: 5 Nisan 2017 Kabul tarihi: 5 Nisan 2017 
Tanısı konulmuş bir servikal patolojiden ötürü uygulanabilecek cerrahi girişimler, anterior, posterior veya kombine şekilde olabilir. Cerrahi tekniğin tipini ve yönünü saptamak için dikkat edilecek kriterleri şu şekilde sıralayabiliriz:

- Tutulan seviyenin lokasyonu ve sayısı.

- Basının özelliği ve yerleşimi.

- Deformite varlığı (kifoz, hiperlordoz, listezis).

- Posterior longitudinal ligaman kalsifikasyonu varlığı.

- Osteoporoz varlığı.

- Eşlik eden diğer hastalıklar.

Radikülopati anterior bası nedeni ile meydana gelmiş ise, hastalık seviyesi üç ve altındaysa, segmental kifoz varsa, konjenital dar kanal yoksa, yumuşak disk hernisi varsa, anterior yaklaşım tercih edilmelidir.

\section{ASDF CERRAHI TEKNIK}

\section{Cerrahi Öncesi Hazırlık}

Operasyon esnasında venöz kanamayı azaltmak için, non-steroid anti-inflamatuvar ilaçların mümkünse bir hafta önceden kesilmesi yararlı olacaktır. Cerrahi öncesi dönemde olası ven trombozunu ve emboliyi engellemek için antiembolik çoraplar giydirilmelidir. Hastaya cerrahi sırasında verilecek boyun pozisyonuna bağlı nörolojik hasar gelişmemesi için, hasta uyanık iken tolere edebileceği fleksiyon ve ekstansiyon sınırları tespit edilmelidir.

\section{Pozisyon}

Hasta, genel anestezi altında ve supin pozisyonda masaya alınır. Hastanın boynu, uyanık iken tolere edebildiği ekstansiyon derecesi kadar ekstansiyona getirilir ve omuzları altına yastık koyularak distal traksiyon sağlanır. Baş nötr pozisyonda tutulur, anestezi hastanın baş kısmında yer alır ve steril örtü ile cerrahi sahadan izole edilir. Cerrah ve asistanı, hastanın boyun kısmında sağlı sollu olarak yer alır.

\section{Cerrahi}

Skopi ile dışardan mesafe tayini yapıldıktan sonra, cerrahın tecrübesine ve dominant kullandığı eline göre hastanın sağından veya solundan, planlanan diskektomi seviye sayısına göre transvers veya oblik insizyon ile cilt ve cilt altı geçilir; platisma cilde paralel veya dik olarak açıı. Biz genellikle, iki seviye üstünde vertikal insizyonu, altında ise transvers insizyonu tercih etmekteyiz. Yüzeyel servikal fasya geçildikten sonra, sternokleidomastoid adale ile omohyoid adale arasından, karotis lateralde, trakea ve özofagus mediyalde kalacak şekilde, keskin ve künt disseksiyon ile derinleşilir. Derin servikal fasya künt disseksiyon ile sıyrılır. Servikal vertebra korpusları ve üzerindeki sağlı sollu longitudinal uzanan longus koli kasları görülür. Skopi ile mesafe tayini yapılır. Mesafe tayininde kullanılan markırların disk mesafesine konulmasının diski bozacağı, enfeksiyon sahası olabileceği akılda tutulmalı ve mesafe penetre edilmemelidir. Sahaya mikroskop çekilir. Bipolar koagülasyon yardımı ile longus kolli adaleleri orta hattan laterale doğru diskektomi mesafesi ortaya konacak şekilde sıyrılır. Bu sıyırma işlemine özellikle C6-C7 mesafesinde dikkat etmek gerekir, aksi takdirde rekürren sinir termal hasarına bağlı ses kısıklığı ile karşılaşılabilir. Disk ve korpus sınırları belirlendikten sonra, üst ve alt korpuslara kaspar ekartör yerleştirilir. Mesafeye distraksiyon uygulanır. Diskektomi posterior longitudinal bağ görülene kadar yapılır. Posterior longitudinal bağ bütünlüğü bozulur ve foramenlere kadar genişletilir. Dura altta görülür, unsinat eklemler ve ossifiye kemikler "Kerrison Rongeur" yardımı ile alınır. Korpus yüzeyleri küretler ve drill yardımı ile end-plate'lerden temizlenir ve dekortike edilir. Mesafe boyu ölçülerek, füzyon amacı ile otogreftler (fibular, iliak kanat), allogreftler, sentetik greftler veya kombinasyonları ile doldurulmuş farklı malzemelerden yapılmış (PEEK [polietereterketon], titanyum, karbon, tantalum) kafes (cage)'ler yerleştirilir (Şekil 1-3).

Ameliyat sırasında yaralanmayı önlemek için, cerrah rekürren laringeal sinirin (RLN) gidişatını bilmelidir. Sağdaki RLN sağ subklaviyan arter çevresinde ve sol RLN aort kemerinin çevresinde döngü yapar. Yaralanması halinde; ses kısıklığı, öksürük, aspirasyon, kitle hissi, disfaji ve vokal kord yorgunluğuna neden olur. Longus kolli adaleleri sıyrılırken laterale fazla gidilmesi halinde, servikal sempatik pleksus etkilenmesi ile Horner sendromu gelişebilir. Kaspar ekartör ile fazla distraksiyon, ameliyat sonrasında boyun ağrısına neden olur. Kullanılan otogreft ile füzyon altın standart yöntem olsa da, greft yerinde gelişebilecek ağrı ve donör bölgesi komplikasyonları göz ardı edilmemelidir.

\section{TARTIŞMA}

ASDF, dekompressif cerrahi ile spinal kord ve köklerin rahatlatıldığı, kafes kullanımı ile füzyonun ve sagittal dengenin sağlandığı, günümüzde omurga cerrahlarının servikal patolojilerde sıklıkla tercih ettikleri bir yöntemdir. Anterior servikal spinal cerrahiyi takiben iyi sonuç, iyi dekompresyon, hızlı ve sağlam kemik füzyonu ve normale en yakın biyomekanik restorasyonun sağlanmasına bağlıdır.

İyi bir klinik sonuç başarılı bir ameliyatın standart belirleyicisi iken, radyolojik füzyon klinik başarının güvenilir bir parametresi değildir. Tamamlanmamış 


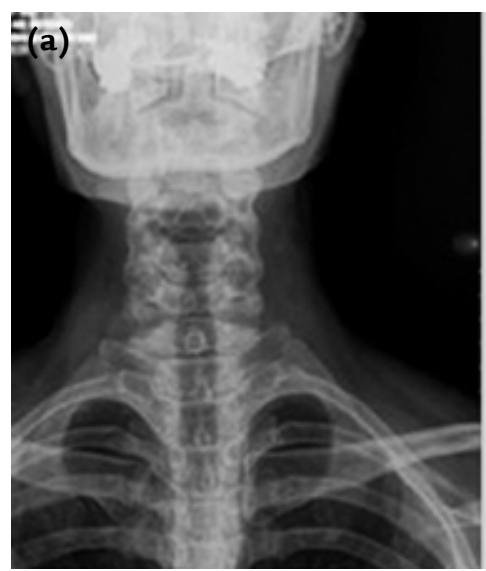

(b)
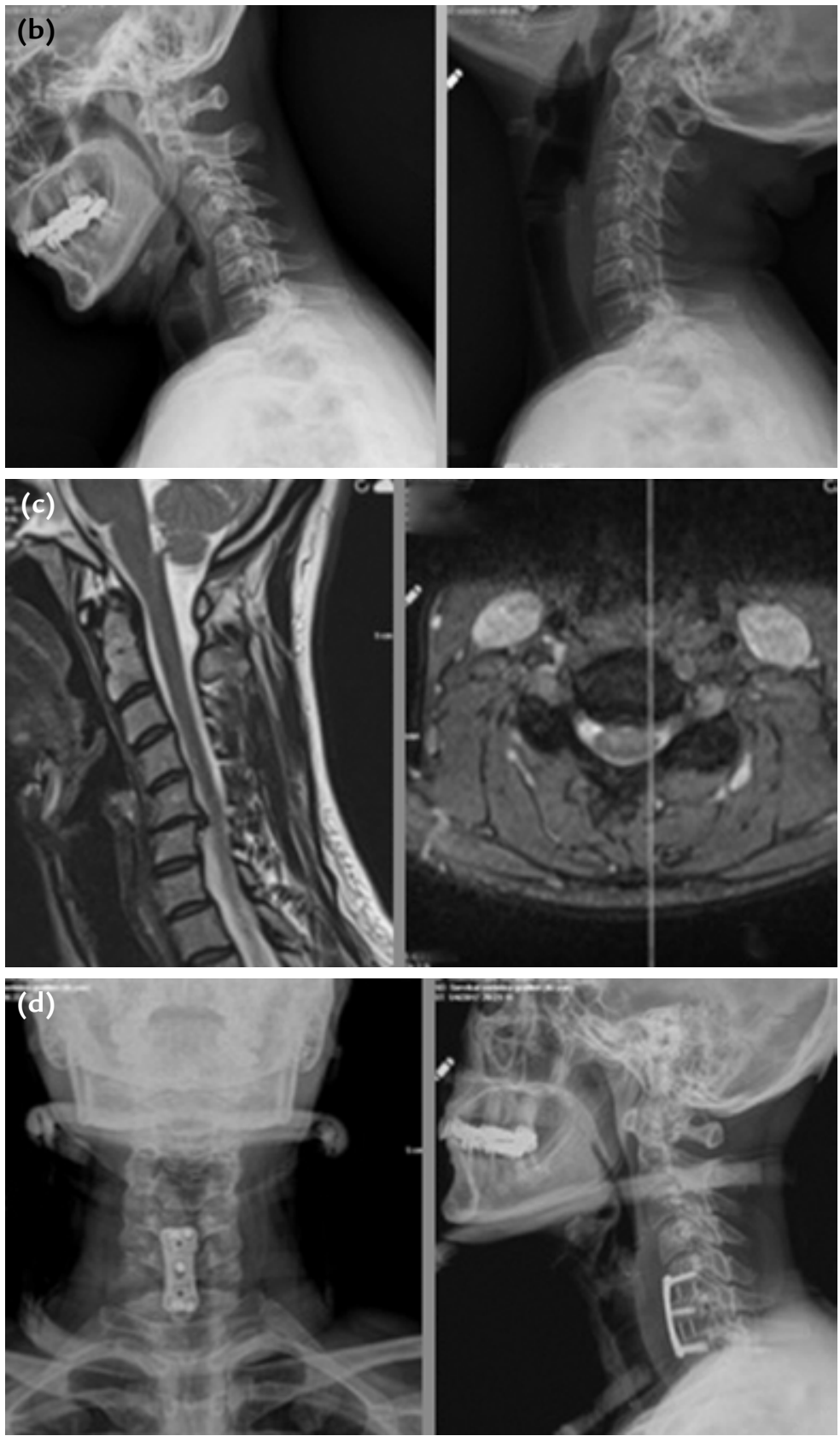

Şekil 1. a-d. Kırk altı yaşında bayan hasta. Boyun ve sağ kolda ağrı, uyuşma, güçsüzlük şikayeti mevcut. Nörolojik muayenesinde sağ kol fleksiyon ve ekstansiyonu $4 / 5$ güçte, derin tendon refleksleri bilateral normoaktif. Operasyon: C5-C6, C6-C7 diskektomi, otogreft ile doldurulmuş PEEK cage yerleştirilmesi, C5-C7 anterior plak ile stabilizasyon. Cerrahi öncesi servikal grafileri (a); cerrahi öncesi fleksiyon, ekstansiyon servikal grafileri (b); cerrahi öncesi servikal MR görüntülemesi (c), cerrahi sonrası servikal grafileri (d). 


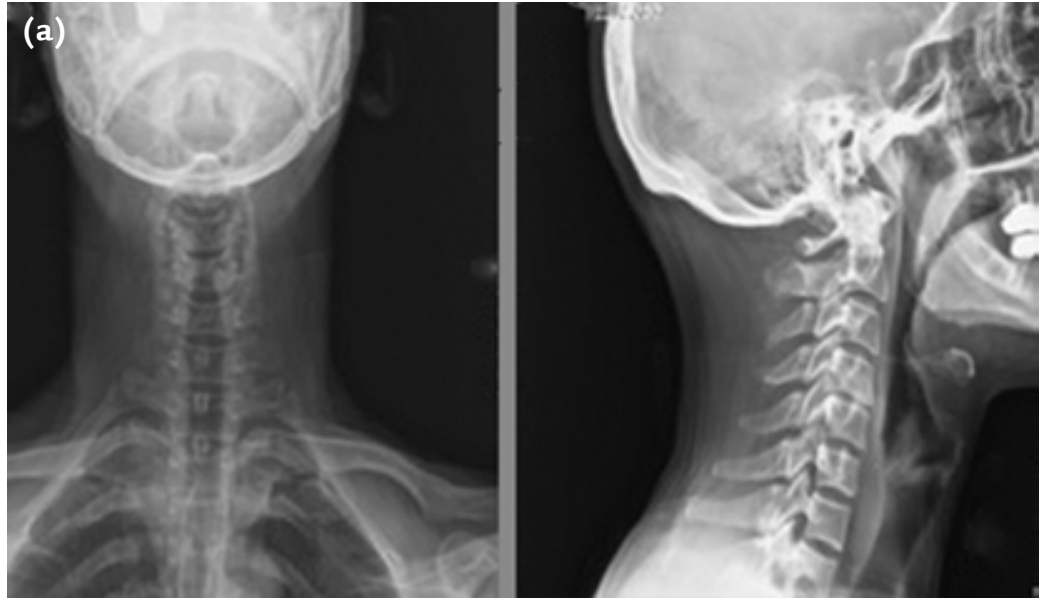

Şekil 2. a-d. Kırk üç yaşında erkek hasta. Boyun ve sağ kol ağrısı şikayeti mevcut. Nörolojik muayenesinde sağ kol fleksiyon 4/5 güçte, derin tendon refleksleri normoaktif. Operasyon: C5C6 diskektomi, otogreft ile doldurulmuş PEEK kafes yerleştirilmesi. Cerrahi öncesi servikal grafileri (a); cerrahi öncesi fleksiyon, ekstansiyon servikal grafileri (b); cerrahi öncesi servikal MR görüntülemesi (c); cerrahi sonrası servikal grafileri (d).
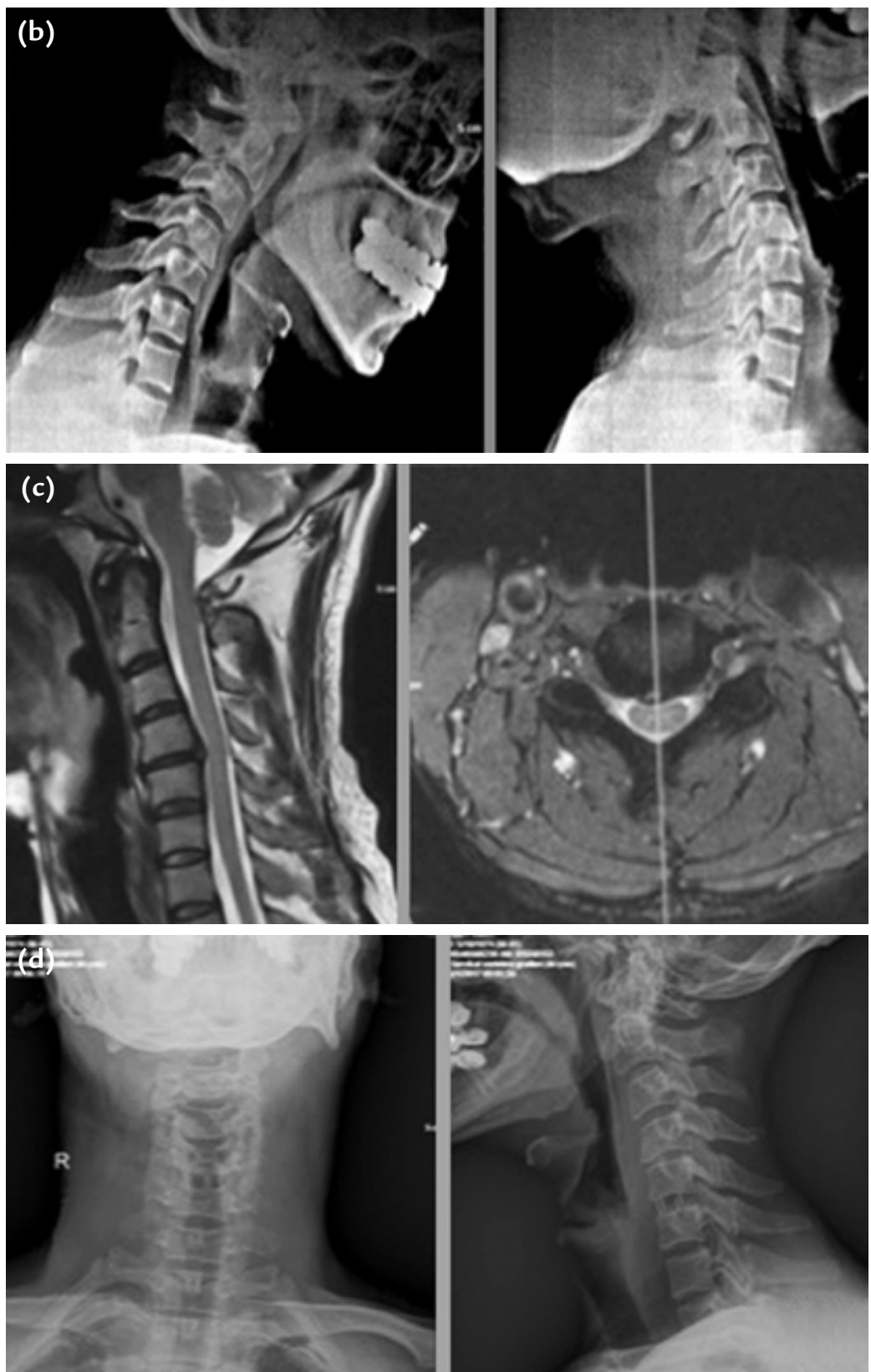

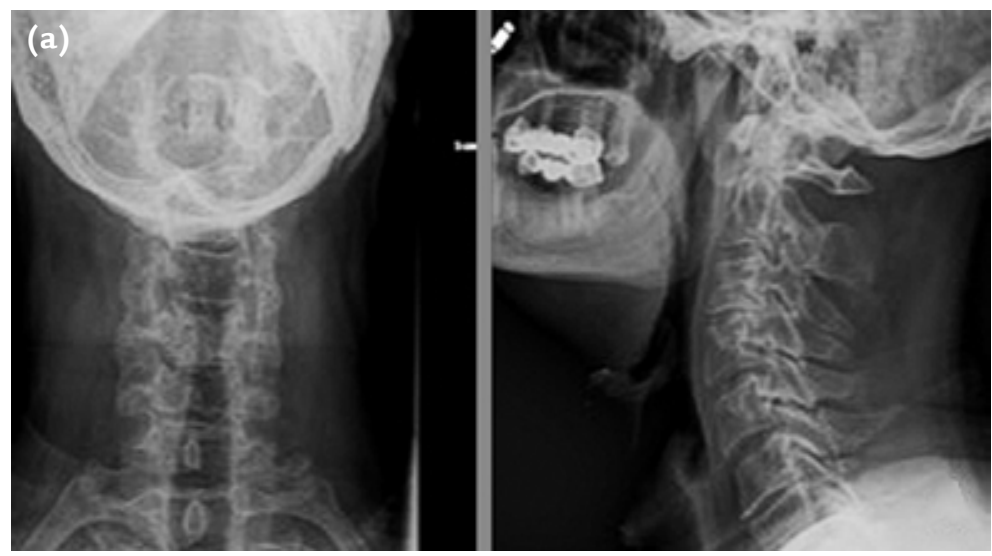

Şekil 3. a-d. Elli sekiz yaşında erkek hasta. Boyun ve sağ kolda ağrı, uyuşma şikayeti mevcut. Nörolojik muayenesinde kas gücü tam, derin tendon refleksleri bilateral normoaktif. Operasyon: C3-C4 diskektomi, otogreft ile doldurulmuş PEEK kafes yerleştirilmesi, C3-C4 anterior plak ile stabilizasyon. Cerrahi öncesi servikal grafileri (a); cerrahi öncesi fleksiyon, ekstansiyon servikal grafileri (b); cerrahi öncesi servikal MR görüntülemesi (c); cerrahi sonrası servikal grafileri (d).
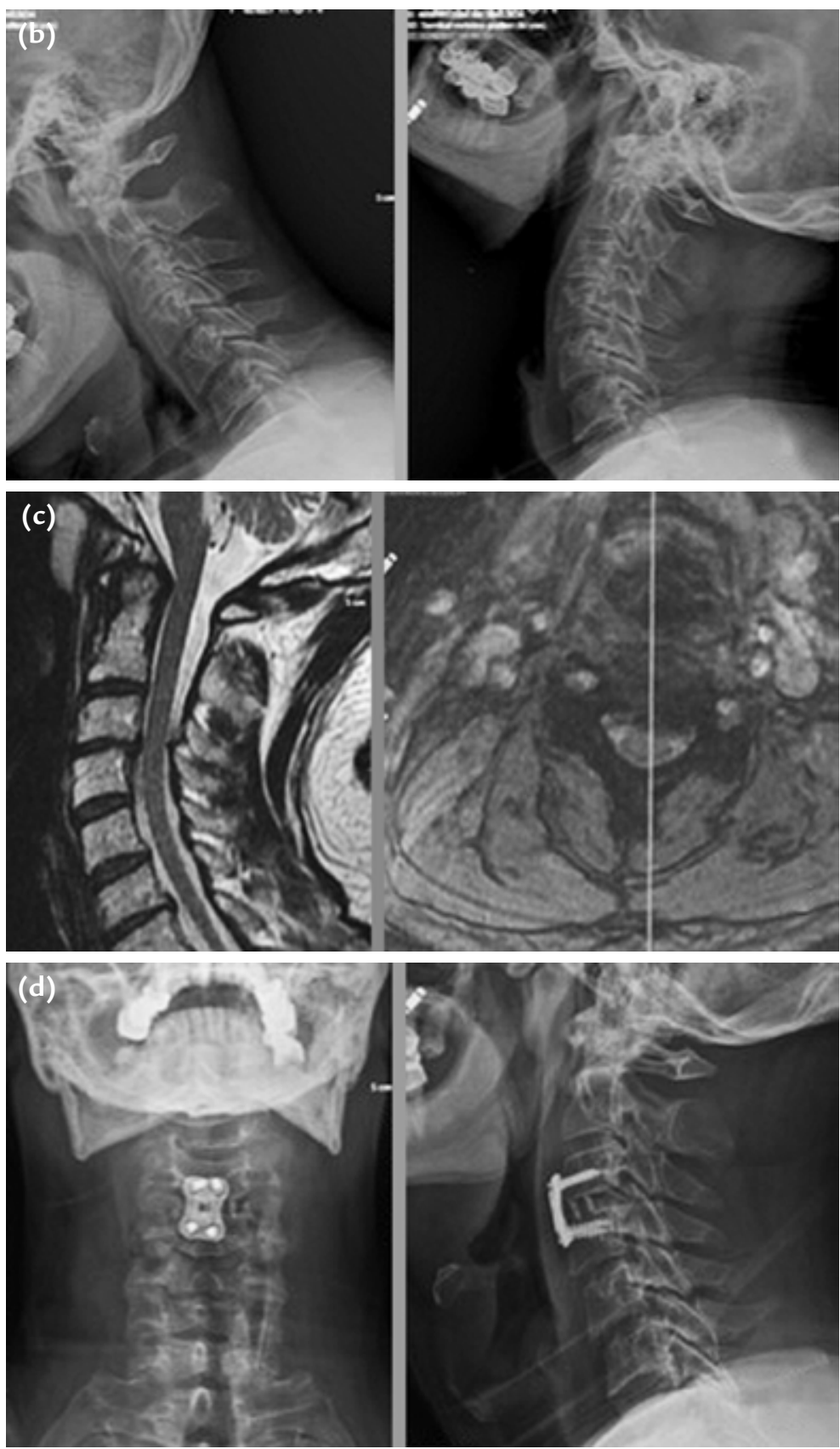
dekompresyona rağmen, radyolojik olarak füzyon elde edilebilir. Başarılı ancak düzensiz kaynama, gecikmiş deformiteye ve sinirsel kompresyonun tekrarlamasına neden olabilir. Omurganın normal eğriliğinde ortaya çıkan kayıp ya da uygunsuz kaynama, komşu mesafede artan stresle sonuçlanır ve komşu mesafedeki diskin hızlandırılmış dejenerasyonuna neden olur.

İyi cerrahi sonuçlara ulaşabilmek için birçok cerrahi malzeme tasarlanmış ve geliştirilmiştir. Anterior servikal cerrahide kullanılan kafeslerin yapıldığı malzemeler arasında; PEEK, titanyum, karbon ve tantalum kafesler sayılabilir. Bu cihazların geliştirilmesindeki asıl amaç, donör bölgesi morbiditesini azaltmak, çok seviyeli cerrahi uygulama yapmayı ve stabilizasyonu sağlayarak osteosentez yapmak ve böylece cerrahi başarı oranlarını arttırmaktır.

Parthiban ve arkadaşları yapmış oldukları çalışmada, ASDF'de otogreft kullanımı ile bir yıl içinde füzyon oranlarını \%98 olarak bildirmişler, ancak üç ay içinde \%2 donör morbiditesi gözlemlemişlerdir. Yazarlar, otogreftin yeni geliştirilmiş cerrahi malzemeleri göze alamayan hastalar için hala en iyi seçim olduğu sonucuna varmışlardır. ${ }^{[9,10]}$ Lied ve arkadaşları, ASDF yaptıkları non-randomize kontrollü ileriye dönük tek merkezli çalışmalarında, trikortikal iliak krest grefti ile PEEK kafes uygulamalarını karşılaştırmışlar; her iki yöntemle yapılan füzyon uygulama sonuçlarının benzer olduğu sonucuna varmışlar; bununla birlikte, PEEK kafes uygulanan hastalarda donör alan morbiditesinin bulunmaması nedeni ile otolog kemik grefti yerine PEEK kafesi ile füzyonu önermişlerdir. ${ }^{[11]}$ Shao ve arkadaşları, servikal dejeneratif disk hastalarında ASDF uygulanan titanyum kafes veya iliak kanat otogrefti kullanılan prosedürlerin etkinliğini ve güvenilirliğini karşılaştırmak için yapmış oldukları çalışmalarında, titanyum kafes kullanılmasının, füzyon ile anterior servikal diskektomi için iliak kanat kemik otogreftlerine göre daha güvenli ve etkili bir alternatif oluşturduğunu bildirmişlerdir. ${ }^{[12]}$

ASDF anterior plakların birlikte kullanımı, interbody grefti veya implantın stabilize edilmesi için 1980 yılından beri kabul edilebilir bir standart haline gelmiştir. Plak, greftin malpozisyonunu engellerken, aynı zamanda greft çökmesine bağlı gelişebilecek kifozu da önler. ${ }^{[13]}$

Richter ve arkadaşları, servikal dejeneratif hastalarda yaptıkları dinamik servikal implant ve ASDF tedavisi için 12 aylık takiplerde elde ettikleri klinik sonuçları her iki prosedür için eşdeğer olarak bulmuşlardır. ${ }^{[14]}$ Füzyon ameliyatlarından sonra, servikal omurganın toplam hareket açıklığı (ROM) azalır ve bitişik segmentin ROM'u artar. İntervertebral diskin ve faset eklemin bitişik segmentlerinin stres piki, bozulmamış servikal vertebranın fizyolojik özelliklerini önemli ölçüde değiştirmek için artar. Bu da, komşu mesafe hastalığı oluşumunun temelinde yatmaktadır. ${ }^{[15]}$ ASDF sonrası semptomatik komşu mesafe hastalığı gelişme oranı yaklaşık olarak \%25'tir. ${ }^{[16]}$ Ancak, tekrar cerrahi gerektirecek komşu seviye hastalığı çok daha azdır. ${ }^{[16]}$

ASDF, günümüz omurga cerrahisi uygulamaları içerisinde yaygın olarak tercih edilen bir prosedürdür ve görünen odur ki uzun yıllar daha tercih edilmeye devam edecektir. ASDF uygulayan cerrahlar için önemli bir öğrenme eğrisi bulunmaktadır. Mayo ve arkadaşları yaptıkları çalışmada, cerrahların ASDF uygulamadaki tahmini yeterliliğini; daha kısa operasyon süresi, daha az kanama ve iyi artrodez yapmalarına göre değerlendirmişler; cerrahi yeterliliğin ortalama 60. olgu ile ortaya çıkmasının beklenebileceği sonucuna varmışlardır. Yapılan çalışma, erken dönemdeki olgularda dahi, ameliyat süresinin uzamasına ve artmış kanamaya rağmen, ASDF'nin bir cerrahın kariyerinin başlangıcında güvenli ve etkili bir şekilde uygulanabileceğini göstermektedir. ${ }^{[17]}$

Sonuç olarak; ASDF, özellikle radikülopatisi olan servikal dejeneratif disk hastalarında, doğru endikasyonlar göz önüne alındığında başarılı ve efektif bir cerrahi işlemdir.

\section{KAYNAKLAR}

1. Smith GW, Robinson RA. The treatment of certain cervicalspine disorders by anterior removal of intervertebral disc and interbody fusion. J Bone Joint Surg Am 1958;40-A(3):607-24.

2. Cloward RB. The anterior approach for removal of ruptured cervical disks. J Neurosurg 1958;15(6):602-17. Crossref

3. Kim HJ, Nemani VM, Piyaskulkaew C, Vargas SR, Riew KD. Cervical Radiculopathy: Incidence and Treatment of 1,420 Consecutive Cases. Asian Spine J 2016;10(2):231-7. Crossref

4. Haden N, Latimer M, Seeley HM, Laing RJ. Loss of intervertebral disc height after anterior cervical discectomy. $\mathrm{Br} J$ Neurosurg 2005;19(6):469-74. Crossref

5. Vavruch L, Hedlund R, Javid D, Leszniewski W, Shalabi A. A prospective randomized comparison between the Cloward procedure and a carbon fiber cage in the cervical spine: a clinical and radiologic study. Spine (Phila Pa 1976) 2002;27(16):1694-701.

6. Bertalanffy $\mathrm{H}$, Eggert HR. Complications of anterior cervical discectomy without fusion in 450 consecutive patients. Acta Neurochir (Wien) 1989;99(1-2):41-50.

7. Siddiqui $A A$, Jackowski A. Cage versus tricortical graft for cervical interbody fusion. A prospective randomized study. J Bone Joint Surg Br 2003;85(7):1019-25.

8. Kwon B, Kim DH, Marvin A, Jenis LG. Outcomes following anterior cervical discectomy and fusion: the role of interbody disc height, angulations, and spinous process distance. J Spinal Disord Tech 2005;18(4):304-8. 
9. Parthiban JKBC. Use of Autograft for Interbody Fusion Following Anterior Cervical Discectomy. In: Ramani PS, Shoda M, Zileli M, Dohrmann GJ, Black P, Brotchi J, editors. WFNS Spine Committee, Surgical Management of Cervical Disc Herniation, 1st ed. New Delhi: JB Medical Publishers; 2012. p.84-90.

10. Massel DH, Mayo BC, Bohl DD, Narain AS, Hijji FY, Fineberg SJ, Louie PK, Basques BA, Long WW, Modi KD, Singh K. Improvements in Neck and Arm Pain Following an Anterior Cervical Discectomy and Fusion. Spine (Phila Pa 1976) 2016. Crossref

11. Lied B, Roenning PA, Sundseth J, Helseth E. Anterior cervical discectomy with fusion in patients with cervical disc degeneration: a prospective outcome study of 258 patients (181 fused with autologous bone graft and 77 fused with a PEEK cage). BMC Surgery 2010;10:10. Crossref

12. Shao $M H$, Zhang F, Yin J, Xu HC, Lyu FZ. Titanium cages versus autogenous iliac crest bone grafts in anterior cervical discectomy and fusion treatment of patients with cervical degenerative diseases: a systematic review and meta-analysis. Curr Med Res Opin 2017;33(5):803-11. Crossref
13. Wang JC, McDonough PW, Endow KK, Delamarter RB. Increased fusion rates with cervical plating for two-level anterior cervical discectomy and fusion. Spine (Phila $\mathrm{Pa}$ 1976) 2000;25(1):41-5.

14. Richter H, Seule M, Hildebrandt G, FournierJY. Dynamic Cervical Implant versus Anterior Cervical Diskectomy and Fusion: A Prospective Study of Clinical and Radiologic Outcome. J Neurol Surg A Cent Eur Neurosurg 2016;77(4):300-7. Crossref

15. Lu T, Zhang T, Dong J, Zang QJ, Yang BH, Wang D, Li HP, He $\mathrm{XJ}$. Impact of anterior cervical fusion surgeries on adjacent segments: a finite element analysis. Nan Fang Yi Ke Da Xue Xue Bao 2017;37(1):49-55.

16. O'Neill KR, Wilson RJ, Burns KM, Mioton LM, Wright BT, Adogwa O, McGirt MJ, Devin CJ. Anterior Cervical Discectomy and Fusion for Adjacent Segment Disease: Clinical Outcomes and Cost Utility of Surgical Intervention. Clin Spine Surg 2016;29(6):234-41. Crossref

17. Mayo BC, Massel DH, Bohl DD, Long WW, Modi KD, Singh K. Anterior Cervical Discectomy and Fusion: The Surgical Learning Curve. Spine (Phila Pa 1976) 2016;41(20):158085. Crossref 